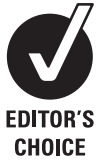

- A supplemental file of QUESTRA collaborators is published online only at http://ard.bmj. com/content/vol68/issue11

For numbered affiliations see end of article

Correspondence to: Dr T Sokka, Arkisto/Tutkijat, Jyväskylä Central Hospital, 40620 Jyväskylä, Finland; tuulikki.sokka@ksshp.fi

Accepted 19 May 2009 Published Online First 31 July 2009

\title{
Disparities in rheumatoid arthritis disease activity according to gross domestic product in 25 countries in the QUEST-RA database
}

\author{
T Sokka, ${ }^{1}$ H Kautiainen, ${ }^{2}$ T Pincus, ${ }^{3}$ S Toloza, ${ }^{4} \mathrm{G}$ da Rocha Castelar Pinheiro, ${ }^{5}$ \\ J Lazovskis, ${ }^{6} \mathrm{M}$ L Hetland, ${ }^{7} \mathrm{~T}$ Peets, ${ }^{8} \mathrm{~K}$ Immonen, ${ }^{9} \mathrm{~J}$ F Maillefert, ${ }^{10}$ A A Drosos, ${ }^{11}$ \\ R Alten, ${ }^{12} \mathrm{C}$ Pohl, ${ }^{12}$ B Rojkovich, ${ }^{13}$ B Bresnihan, ${ }^{14}$ P Minnock, ${ }^{15}$ M Cazzato, ${ }^{16}$ \\ S Bombardieri, ${ }^{16}$ S Rexhepi, ${ }^{17}$ M Rexhepi, ${ }^{17} \mathrm{D}$ Andersone, ${ }^{18}$ S Stropuviene, ${ }^{19}$ \\ M Huisman, ${ }^{20}$ S Sierakowski, ${ }^{21}$ D Karateev ${ }_{1}{ }^{22}$ V Skakic, ${ }^{23}$ A Naranjo, ${ }^{24}$ E Baecklund, ${ }^{25}$ \\ D Henrohn, ${ }^{25} \mathrm{~F}$ Gogus ${ }^{26} \mathrm{H}^{26}$ Badsha,${ }^{27} \mathrm{~A}$ Mofti, ${ }^{28} \mathrm{P}$ Taylor, ${ }^{29} \mathrm{C} \mathrm{McClinton},{ }^{29} \mathrm{Y} \mathrm{Yazici}^{3}$
}

\section{ABSTRACT}

Objective: To analyse associations between the clinical status of patients with rheumatoid arthritis (RA) and the gross domestic product (GDP) of their resident country. Methods: The Quantitative Standard Monitoring of Patients with Rheumatoid Arthritis (QUEST-RA) cohort includes clinical and questionnaire data from 6004 patients who were seen in usual care at 70 rheumatology clinics in 25 countries as of April 2008, including 18 European countries. Demographic variables, clinical characteristics, RA disease activity measures, including the disease activity score in 28 joints (DAS28), and treatment-related variables were analysed according to GDP per capita, including 14 "high GDP" countries with GDP per capita greater than US\$24 000 and 11 "low GDP" countries with GDP per capita less than US\$11 000. Results: Disease activity DAS28 ranged between 3.1 and 6.0 among the 25 countries and was significantly associated with GDP ( $r=-0.78,95 \% \mathrm{Cl}-0.56$ to $-0.90, r^{2}=61 \%$ ). Disease activity levels differed substantially between "high GDP" and "low GDP" countries at much greater levels than according to whether patients were currently taking or not taking methotrexate, prednisone and/or biological agents.

Conclusions: The clinical status of patients with RA was correlated significantly with GDP among 25 mostly European countries according to all disease measures, associated only modestly with the current use of antirheumatic medications. The burden of arthritis appears substantially greater in "low GDP" than in "high $\mathrm{GDP}^{\prime \prime}$ countries. These findings may alert healthcare professionals and designers of health policy towards improving the clinical status of patients with RA in all countries.

Health disparities, including high mortality rates, are associated with low socioeconomic status in many specific diseases in many countries. ${ }^{1-6}$ Furthermore, differences in gross domestic product (GDP) in different countries are associated significantly with differences in mortality rates among countries. ${ }^{7-9}$ Most reports of these observations are based on surveys and national databases, with relatively limited information from clinical settings based on physical examination, laboratory tests, medications and patient self-report information concerning functional status, pain, psychosocial distress, etc, to understand further the basis for these disparities. Furthermore, little is known concerning associations of GDP and clinical outcomes of chronic disabling musculoskeletal conditions such as rheumatoid arthritis (RA).

A multinational database Quantitative Standard Monitoring of Patients with Rheumatoid Arthritis (QUEST-RA) ${ }^{10} 11$ was established to assess 100 unselected consecutive patients with RA per clinic and included 25 countries by April 2008. Considerable variation was observed in clinical status in different countries according to most clinical measures, whether derived from the physician, patient or laboratory, as well as the composite RA disease activity score in 28 joints (DAS28) index. ${ }^{12}$ In this report, we compare demographic characteristics, RA disease activity measures and treatment-related variables between "high GDP" and "low GDP" countries, and analyse associations between DAS28 and GDP.

\section{PATIENTS AND METHODS}

\section{Establishment of database}

QUEST-RA was established in 2005 with the objectives of promoting quantitative assessment in usual rheumatology care, and to develop a baseline cross-sectional database of consecutive RA patients seen outside of clinical trials in regular care in many countries. Three or more rheumatologists were asked to enroll 100 consecutive unselected patients in each country. ${ }^{10}$ As of April 2008, the programme enrolled 6004 patients from 71 sites in 25 countries, including Argentina, Brazil, Canada, Denmark, Estonia, Finland, France, Germany, Greece, Hungary, Ireland, Italy, Kosovo, Latvia, Lithuania, The Netherlands, Poland, Russia, Serbia, Spain, Sweden, Turkey, United Arab Emirates, the UK and the USA. ${ }^{11}$

The study was carried out in compliance with the Helsinki Declaration. Ethics Committees or Internal Review Boards of participating institutes approved the study, and a written informed consent was obtained from the patients.

\section{Physician assessment measures}

All patients were assessed according to a standard protocol to evaluate RA. ${ }^{13}$ The physician review 
included a formal examination to count the number of swollen and tender joints, report of radiographic erosions, erythrocyte sedimentation rate (ESR) and rheumatoid factor (RF) positivity according to local reference values. Physicians reported the use of disease-modifying antirheumatic drugs (DMARD), including: (1) the interval between the first symptoms and the start of the first DMARD; (2) the number of DMARD ever used; (3) the use of methotrexate, oral glucocorticoids, biological agents and other DMARD and (4) the start and stop dates for each DMARD used. The total duration of DMARD therapy as a percentage of disease duration was computed.

\section{Patient self-report questionnaire measures}

Patients completed a 4-page self-report questionnaire, which included demographic data, physical function, pain, global estimate and psychological distress. Demographic data included date of birth, gender, years of formal education, race and smoking status, as well as weight and height, to calculate body mass index (BMI). A standard health assessment questionnaire $(\mathrm{HAQ})^{14}$ assesses physical function in activities of daily living with four response categories: 0 , without any difficulty; 1 , with some difficulty; 2 , with much difficulty; 3 , unable to do. Visual analogue scales $(0=$ best to $10=$ worst) were completed for pain and patient estimate of his/her global health (GH). Psychological distress was assessed as the capacity to cope with stress, anxiety and depression, queried and calculated in the $\mathrm{HAO}$ format for psychological HAQ scored $0-3 .{ }^{15}$

\section{Disease activity score}

The DAS28 ${ }^{12}$ is the most widely used overall measure for RA disease activity, comprising two physical examination measures, a swollen 28-joint count (SJC28) and a tender 28-joint count (TJC28); one laboratory measure, ESR; and one patient self-report measure, a global estimate of health status $(\mathrm{GH})$. DAS28 ranges from 0 to 9.1 (low-high), calculated from the

Table 1 Comparison of patient characteristics, RA disease activity measures and treatment-related variables in the QUEST-RA study in "high GDP" and "low GDP" countries

\begin{tabular}{|c|c|c|c|c|}
\hline & Total & $\begin{array}{l}\text { "High GDP" } \\
\text { countries }\end{array}$ & $\begin{array}{l}\text { "Low GDP" } \\
\text { countries }\end{array}$ & p Value* \\
\hline $\mathrm{N}$ & 6004 & 3719 & 2285 & \\
\hline \multicolumn{5}{|l|}{ Patient characteristics } \\
\hline Female, \% & $79 \%$ & $75 \%$ & $86 \%$ & $<0.001$ \\
\hline Age, years, mean & 56 & 58 & 54 & $<0.001$ \\
\hline Education, years, median & 11 & 11 & 11 & 0.16 \\
\hline Smoking now, \% & $17 \%$ & $19 \%$ & $14 \%$ & $<0.001$ \\
\hline BMI, mean & 26 & 26 & 26 & 0.63 \\
\hline Disease duration, years, mean & 11 & 11 & 11 & 0.038 \\
\hline \multicolumn{5}{|l|}{ Disease activity measures } \\
\hline DAS28 (0-9.1), mean & 4.2 & 3.7 & 5.1 & $<0.001$ \\
\hline \multicolumn{5}{|l|}{ Physician } \\
\hline SJC (0-28), median & 2 & 1 & 4 & $<0.001$ \\
\hline TJC (0-28), median & 4 & 2 & 8 & $<0.001$ \\
\hline Physician global (0-10), median & 2.4 & 1.7 & 3.7 & $<0.001$ \\
\hline \multicolumn{5}{|l|}{ Patient self-report } \\
\hline HAO physical function (0-3) median & 0.88 & 0.75 & 1.3 & $<0.001$ \\
\hline Pain VAS (0-10), median & 4.1 & 3.3 & 4.9 & $<0.001$ \\
\hline Patient global VAS $(0-10)$, median & 4.2 & 3.2 & 4.9 & $<0.001$ \\
\hline Psychological HAO (0-3), mean & 0.82 & 0.7 & 1.3 & $<0.001$ \\
\hline \multicolumn{5}{|l|}{ Laboratory/imaging } \\
\hline ESR, median & 22 & 18 & 30 & $<0.001$ \\
\hline RF-positive, \% & $74 \%$ & $72 \%$ & $76 \%$ & 0.001 \\
\hline Erosive disease, \% & $63 \%$ & $58 \%$ & $72 \%$ & $<0.001$ \\
\hline In patients with disease duration $\leqslant 2$ years & & $23 \%$ & $40 \%$ & $<0.001$ \\
\hline In patients with disease duration $\geqslant 10$ years & & $79 \%$ & $84 \%$ & 0.001 \\
\hline \multicolumn{5}{|l|}{ Treatment-related variables } \\
\hline Patients taking DMARD ever, \% & $97 \%$ & $97 \%$ & $97 \%$ & 0.75 \\
\hline Delay to start a DMARD, months, median & 9 & 9 & 9 & 0.063 \\
\hline No of DMARD ever taken, mean & 2.7 & 2.8 & 2.5 & $<0.001$ \\
\hline Methotrexate ever, $\%$ of patients & $85 \%$ & $86 \%$ & $84 \%$ & $<0.001$ \\
\hline Methotrexate now, $\%$ of patients & $63 \%$ & $63 \%$ & $62 \%$ & 0.36 \\
\hline Prednisone ever, $\%$ of patients & $71 \%$ & $66 \%$ & $80 \%$ & $<0.001$ \\
\hline Prednisone now, $\%$ of patients & $49 \%$ & $42 \%$ & $60 \%$ & $<0.001$ \\
\hline Biologicals ever, $\%$ of patients & $23 \%$ & $31 \%$ & $9.4 \%$ & $<0.001$ \\
\hline Biologicals now, $\%$ of patients & $18 \%$ & $25 \%$ & $7.5 \%$ & $<0.001$ \\
\hline Any DMARD, \% of disease duration & $72 \%$ & $75 \%$ & $67 \%$ & 0.085 \\
\hline Methotrexate, $\%$ of disease duration & $31 \%$ & $32 \%$ & $30 \%$ & 0.18 \\
\hline Biologicals, $\%$ of disease duration & $3.9 \%$ & $5.6 \%$ & $1.8 \%$ & 0.001 \\
\hline
\end{tabular}

*Unadjusted $\mathrm{p}$ values are presented.

BMI, body mass index; DAS28, disease activity score in 28 joints; DMARD, disease-modifying antirheumatic drug; ESR,

erythrocyte sedimentation rate; GDP, gross domestic product; HAQ, health assessment questionnaire; RA, rheumatoid arthritis; RF, rheumatoid factor; SJC, swollen joint count; TJC, tender joint count; VAS, visual analogue scale. 
formula $0.56^{*} \operatorname{sqrt}(\mathrm{TJC} 28)+0.28^{*} \operatorname{sqrt}(\mathrm{SJC} 28)+0.70^{*} \operatorname{Ln}(\mathrm{ESR})+$ $0.014^{*}(\mathrm{GH})$.

\section{Gross domestic product}

The GDP of each country in 2005 was obtained from a database of the International Monetary Fund ${ }^{16}$ and is expressed as UD\$1000 or Euros $(€)$ per capita (with an exchange rate of US\$1.25 = €1.0 in 2005). GDP ranged from 3.5 to 49 , including 14 "high GDP" countries with GDP per capita greater than US\$24 000 and 11 "low GDP" countries with GDP per capita less than US\$11 000 .

\section{Statistical methods}

Descriptive results for each country are presented as mean, median and percentages. Comparisons of demographic variables, clinical characteristics, RA disease activity measures and treatment-related variables within and/or between "high GDP" and "low GDP" countries were performed using parametric and non-parametric tests for continuous variables and the $\chi^{2}$ test for categorical variables. Linear regression models were applied to analyse possible associations between DAS28 and GDP.

\section{RESULTS}

\section{Patients}

The 6004 patients in the QUEST-RA database, from 71 clinics in 25 countries, represent a typical RA cohort in demographic features, with a mean age of 56 years, $79 \%$ women, and a mean disease duration of 11 years (table 1). Patients were younger and more likely to be women in "low GDP" compared with "high GDP" countries, whereas years of formal education, BMI and disease duration were similar (table 1). Patient characteristics are presented for each European and non-European country, in descending order of GDP in table 2.

\section{Disease activity}

Patients in "low GDP" countries had statistically significantly higher disease activity levels in all individual disease activity measures, including physician-derived measures, patient selfreport scores and laboratory measures, as well as the composite index DAS28 (table 1). The percentage of patients with positive RF varied between $61 \%$ and $90 \%$ between countries (table 3 ), although the overall difference was only $4 \%$ between "high GDP" and "low GDP" countries (table 1). Erosive disease was less prevalent in "high GDP" countries, with differences of $14 \%$, although with differences of only $5 \%$ in patients with more than 10 years of disease (table 1 ).

\section{Drug therapies}

DMARD were taken by $88-100 \%$ of all patients in the 25 countries (table 4), with no differences between "high GDP" and "low GDP" countries (table 1); the mean number of DMARD was 2.7. The median delay between first symptoms and initiation of the first DMARD ranged from less than 6 months in three countries to one year or more in 10 countries (table 4), with no significant difference between "high GDP" and "low GDP" countries (table 1). Methotrexate was taken by $69-98 \%$, prednisone by $30-97 \%$ and biological agents by $1-54 \%$ of patients. DMARD were taken for less than $50 \%$ of disease duration in the UK, Ireland, Hungary, Latvia, Lithuania and Argentina, and for more than $100 \%$ in Finland, Greece and

Table 2 Patient characteristics in the QUEST-RA study in Europe and other countries, in descending order of GDP

\begin{tabular}{|c|c|c|c|c|c|c|c|c|c|}
\hline Country & $\begin{array}{l}\text { GDP } 2005 \text { per } \\
\text { capita } \\
\text { (US\$1000) }\end{array}$ & Sites & Patients & Women, \% & $\begin{array}{l}\text { Age, years, } \\
\text { mean }\end{array}$ & $\begin{array}{l}\text { Education, } \\
\text { years, } \\
\text { median }\end{array}$ & $\begin{array}{l}\text { Smoking } \\
\text { now, \% }\end{array}$ & BMI, mean & $\begin{array}{l}\text { Disease } \\
\text { duration, } \\
\text { years, mean }\end{array}$ \\
\hline \multicolumn{10}{|l|}{ Europe } \\
\hline Ireland & 48.7 & 3 & 240 & 64 & 56 & 12 & 24 & 25 & 11 \\
\hline Denmark & 47.9 & 3 & 301 & 77 & 58 & 10 & 31 & 25 & 12 \\
\hline Sweden & 39.6 & 3 & 260 & 72 & 59 & 10 & 19 & 25 & 12 \\
\hline The Netherlands & 38.9 & 3 & 317 & 66 & 59 & 11 & 22 & 26 & 9 \\
\hline Finland & 37.3 & 3 & 304 & 72 & 59 & 9 & 15 & 27 & 14 \\
\hline UK & 37.3 & 3 & 145 & 78 & 60 & 12 & 19 & 25 & 15 \\
\hline France & 35.0 & 4 & 389 & 78 & 55 & 10 & 19 & 25 & 13 \\
\hline Germany & 33.9 & 2 & 225 & 84 & 59 & 10 & 13 & 26 & 13 \\
\hline Italy & 30.5 & 4 & 336 & 78 & 61 & 8 & 16 & 25 & 10 \\
\hline Spain & 26.1 & 3 & 302 & 74 & 60 & 10 & 17 & 26 & 11 \\
\hline Greece & 25.6 & 3 & 300 & 76 & 58 & 12 & 15 & 26 & 12 \\
\hline Hungary & 10.9 & 3 & 153 & 87 & 58 & 12 & 24 & 25 & 13 \\
\hline Estonia & 10.3 & 3 & 168 & 85 & 56 & 12 & 14 & 26 & 12 \\
\hline Poland & 8.0 & 7 & 642 & 87 & 53 & 12 & 11 & 25 & 12 \\
\hline Lithuania & 7.5 & 2 & 300 & 83 & 54 & 13 & 7 & 26 & 11 \\
\hline Latvia & 7.0 & 1 & 79 & 80 & 53 & 13 & 18 & 27 & 13 \\
\hline Serbia & 3.5 & 1 & 100 & 88 & 59 & 8 & 18 & 26 & 10 \\
\hline Kosovo & 3.5 & 1 & 100 & 84 & 55 & 8 & 5 & 28 & 8 \\
\hline \multicolumn{10}{|l|}{ Non-Europe } \\
\hline USA & 41.9 & 3 & 301 & 73 & 57 & 13 & 20 & 28 & 9 \\
\hline Canada & 35.2 & 1 & 100 & 79 & 58 & 12 & 30 & 27 & 12 \\
\hline UAE & 32.4 & 2 & 199 & 86 & 45 & 15 & 6 & 26 & 6 \\
\hline Russia & 5.3 & 3 & 73 & 85 & 54 & 13 & 15 & 26 & 6 \\
\hline Turkey & 5.0 & 3 & 309 & 86 & 52 & 5 & 13 & 27 & 12 \\
\hline Brazil & 4.8 & 5 & 115 & 89 & 52 & 8 & 13 & 25 & 8 \\
\hline Argentina & 4.7 & 2 & 246 & 90 & 51 & 9 & 21 & 26 & 10 \\
\hline Total & & 71 & 6004 & 79 & 56 & 11 & 17 & 26 & 11 \\
\hline
\end{tabular}

BMI, body mass index; GDP, gross domestic product; UAE, United Arab Emirates. 
Table 3 RA measures in the QUEST-RA study in Europe and other countries, in descending order of GDP

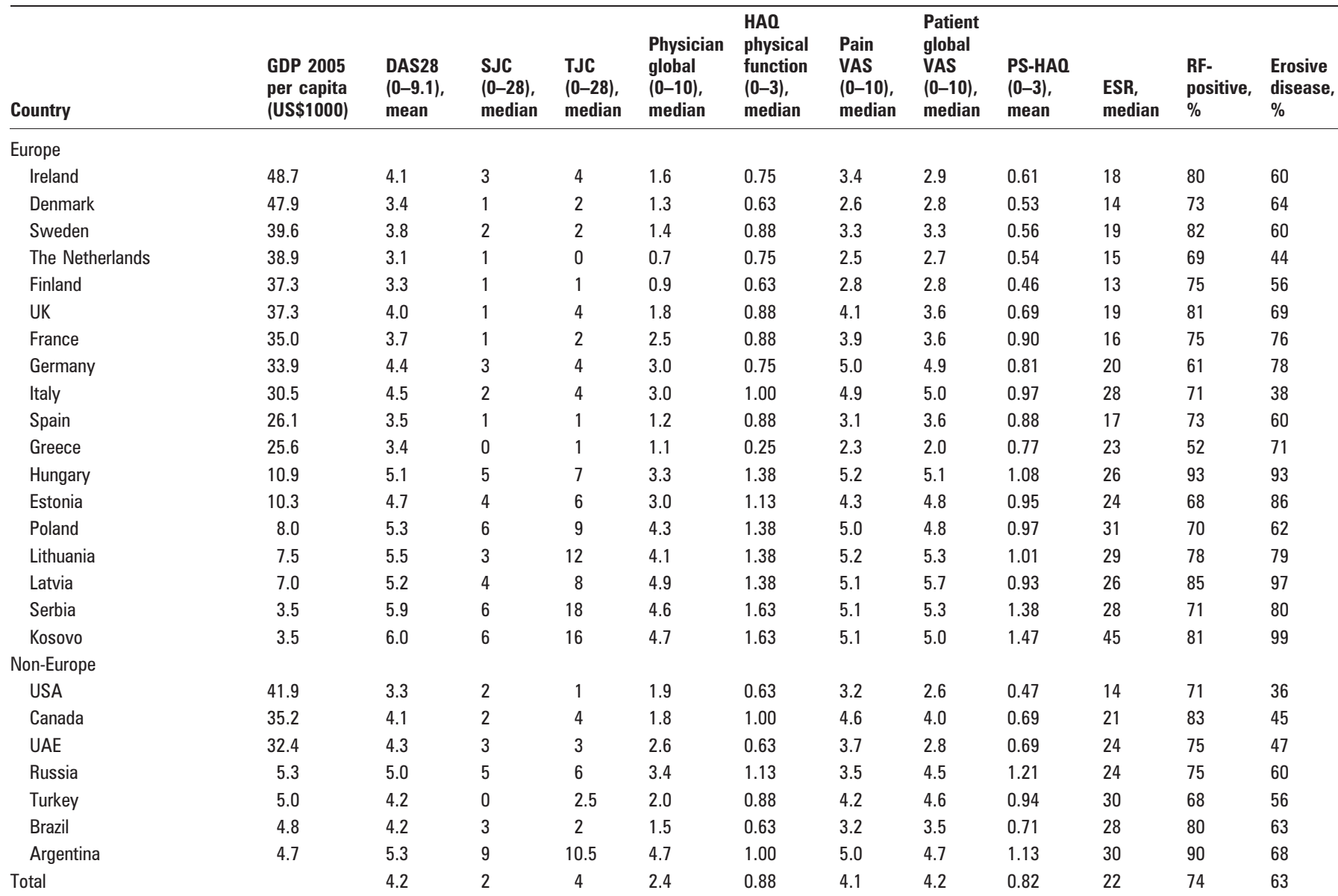

DAS28, disease activity score in 28 joints; ESR, erythrocyte sedimentation rate; GDP, gross domestic product; HAQ, health assessment questionnaire; Physician global, physician global estimate of status; PS-HAQ, psychological HAQ; RA, rheumatoid arthritis; RF, rheumatoid factor; SJC, swollen joint count; TJC, tender joint count; UAE, United Arab Emirates; VAS, visual analogue scale.

Brazil-percentages greater than 100 indicate the simultaneous use of two or more DMARD. Methotrexate covered $21-57 \%$ of disease duration and the use of biologic agents covered $0.2-14 \%$ (table 4).

Differences in the DAS28 scores of patients who were taking or not taking methotrexate were small within "high GDP" countries (3.6 vs 3.8) and "low GDP" countries (5.1 vs 5.2) but large between "high GDP" versus "low GDP" countries $(p<0.001$; table 5). Similar patterns were seen for patients who were currently taking or not taking prednisone. Patients who were taking or not taking biological agents in "high GDP" countries had similar disease activity levels of 3.7, whereas in "low GDP" countries those who were taking biological agents had a statistically significantly lower mean DAS28 of 4.4 compared with patients who were not taking biological agents (DAS28 5.2; $<<0.001$ ).

\section{Linear regression models for GDP and disease activity}

The mean DAS28 varied among countries from 3.1 to 6.0 (table 2), and was associated significantly with GDP ( $\mathrm{r}=-0.78,95 \% \mathrm{CI}-0.56$ to $-0.90, \mathrm{r}^{2}=61 \%$ ); a stronger association ( $r=-0.85,95 \%$ CI -0.63 to $-0.94, r^{2}=72 \%$ ) was seen when only 18 European countries were included (fig 1; data from USA presented as a reference in the figure). Among European countries, an increase of GDP per $1000 €$ translates to a decrease of DAS28 of -0.10 (95\% CI -0.061 to -0.13$)$.

\section{DISCUSSION}

These data from the QUEST-RA database indicate that the burden of RA is substantially greater in "low GDP" than in "high GDP" countries, within and outside of Europe. These results are consistent with data concerning other chronic diseases and general health in different countries. ${ }^{7-9} 17$ The burden of chronic diseases, recognised as an important neglected global health issue, ${ }^{18}$ is greatest in low and middle income countries. ${ }^{19}$ Most chronic diseases occur at substantially higher frequency in individuals of low socioeconomic status, particularly before the age of 65 years. ${ }^{1-6}$ Poor outcomes of RA including mortality are associated with low socioeconomic status. $^{50}$

Associations of low socioeconomic status and poor health, within and between countries, are regarded in most medical literature as based primarily on limited access to medical care and problems in the structure of clinical care, ${ }^{21-23}$ reflecting a "biomedical model", the dominant paradigm of 20th century medicine. ${ }^{23} 24$ However, in the present study, all patients had access to a rheumatologist, and $88-100 \%$ of patients had taken DMARD, including 69-98\% who had taken methotrexate. Treatment-related variables were quite similar between "high GDP" and "low GDP" countries, including $97 \%$ of patients who had used DMARD, a delay of 9 months to the start of DMARD after first symptoms, the number of DMARD ever taken (2.8 and 2.5 ); $86 \%$ and $84 \%$ had ever used methotrexate and the use of methotrexate covered similarly $32 \%$ and $30 \%$ of disease 
Table 4 GDP and treatment-related variables in the QUEST-RA study in Europe and other countries, in descending order of GDP

\begin{tabular}{|c|c|c|c|c|c|c|c|c|c|c|}
\hline Country & $\begin{array}{l}\text { GDP } 2005 \\
\text { per capita } \\
\text { US } \$ 1000\end{array}$ & $\begin{array}{l}\text { Patients } \\
\text { taking } \\
\text { DMARD } \\
\text { ever, \% }\end{array}$ & $\begin{array}{l}\text { Delay to start } \\
\text { DMARD, } \\
\text { months, } \\
\text { median }\end{array}$ & $\begin{array}{l}\text { No of } \\
\text { DMARD } \\
\text { ever taken }\end{array}$ & $\begin{array}{l}\text { Methotrexate } \\
\text { ever, \% of } \\
\text { patients }\end{array}$ & $\begin{array}{l}\text { Prednisone } \\
\text { ever, \% of } \\
\text { patients }\end{array}$ & $\begin{array}{l}\text { Biologicals } \\
\text { ever, \% of } \\
\text { patients }\end{array}$ & $\begin{array}{l}\text { Any DMARD, } \\
\% \text { of disease } \\
\text { duration }\end{array}$ & $\begin{array}{l}\text { Methotrexate, } \\
\% \text { of disease } \\
\text { duration }\end{array}$ & $\begin{array}{l}\text { Biologicals, } \\
\% \text { of } \\
\text { disease } \\
\text { duration }\end{array}$ \\
\hline Ireland & 48.7 & 98.0 & 10.0 & 2.4 & 93 & 71 & 42 & 55.7 & 28.9 & 6.6 \\
\hline Denmark & 47.9 & 99.0 & 10.0 & 2.8 & 86 & 44 & 23 & 65.6 & 25.5 & 2.9 \\
\hline Sweden & 39.6 & 94.0 & 12.0 & 2.8 & 84 & 69 & 33 & 73.7 & 31.1 & 7.2 \\
\hline UK & 37.3 & 95.0 & 12.0 & 2.4 & 83 & 54 & 20 & 51.3 & 24.6 & 1.9 \\
\hline France & 35.0 & 99.0 & 8.0 & 3.7 & 87 & 83 & 53 & 77.0 & 31.0 & 8.9 \\
\hline Germany & 33.9 & 92.0 & 15.0 & 2.7 & 80 & 54 & 29 & 66.5 & 28.8 & 6.3 \\
\hline Italy & 30.5 & 96.0 & 9.0 & 2.4 & 81 & 72 & 27 & 66.9 & 28.9 & 2.9 \\
\hline Spain & 26.1 & 98.0 & 13.0 & 2.8 & 87 & 68 & 27 & 67.4 & 30.9 & 4.4 \\
\hline Greece & 25.6 & 100.0 & 7.0 & 2.9 & 94 & 94 & 54 & 104.2 & 50.8 & 14.6 \\
\hline Latvia & 7.0 & 98.0 & 24.0 & 2.2 & 92 & 79 & 23 & 52.9 & 28.0 & 1.6 \\
\hline Serbia & 3.5 & 96.0 & 11.0 & 2.0 & 69 & 88 & 2 & 64.6 & 25.2 & 0.3 \\
\hline Kosovo & 3.5 & 100.0 & 3.0 & 2.0 & 82 & 95 & 1 & 82.4 & 36.8 & 0.2 \\
\hline \multicolumn{11}{|l|}{ Non-Europe } \\
\hline USA & 41.9 & 98 & 9.0 & 2.1 & 85 & 77 & 33 & 83.8 & 39.5 & 8.5 \\
\hline Canada & 35.2 & 95 & 11.0 & 3.0 & 76 & 62 & 28 & 77.6 & 22.1 & 5.0 \\
\hline UAE & 32.4 & 88 & 11.0 & 1.8 & 73 & 56 & 10 & 70.2 & 31.3 & 1.9 \\
\hline Russia & 5.3 & 88 & 10.0 & 1.8 & 73 & 41 & 18 & 64.0 & 28.6 & 9.7 \\
\hline Turkey & 5 & 99 & 12.0 & 2.4 & 89 & 75 & 7 & 75.3 & 33.4 & 0.7 \\
\hline Brazil & 4.8 & 100 & 8.0 & 3.0 & 98 & 81 & 27 & 115.7 & 57.6 & 3.7 \\
\hline Argentina & 4.7 & 88 & 13.0 & 1.5 & 68 & 83 & 3 & 46.3 & 24.5 & 0.5 \\
\hline Total & & 97 & 9 & 2.7 & 85 & 71 & 23 & 71.6 & 30.8 & 3.9 \\
\hline
\end{tabular}

DMARD, disease-modifying antirheumatic drug; GDP, gross domestic product; UAE, United Arab Emirates.

duration in "high GDP" and "low GDP" countries. Disease activity levels appeared much more associated with the wealth of the country than current medications (table 5). The current use of biological agents appeared to have a greater inverse association with disease activity in "low GDP" than in "high GDP" countries (table 5).

GDP explained $61 \%$ of the variation in DAS28 scores, consistent with extensive observations of differences in health status and mortality in different nations according to a nation's wealth. $^{7-9}$ Differences in DAS28 scores according to GDP are at least twice as great as improvements in DAS28 achieved in any clinical trial of the most powerful biological agents. The data echo a suggestion made by Virchow in 1848 that "the improvement of medicine would eventually prolong human life, but improvement of social conditions could achieve this result now more rapidly and more successfully." 25

Many psychological constructs, including stress, anxiety, depression, limited social support, learned helplessness and lack of optimism, are prognostic of higher mortality rates in individuals. ${ }^{23}{ }^{26-28}$ These reports suggest that associations of low

Table 5 Disease activity in "high GDP" and "low GDP" countries, according to current medications

\begin{tabular}{|c|c|c|c|}
\hline & "High GDP" countries & "Low GDP" countries & \\
\hline & DAS28, mean & DAS28, mean & p Value $\dagger$ \\
\hline \multicolumn{4}{|l|}{ Methotrexate } \\
\hline Taking methotrexate now & 3.6 & 5.1 & $<0.001$ \\
\hline No methotrexate now & 3.8 & 5.2 & $<0.001$ \\
\hline p Value* & 0.003 & 0.028 & \\
\hline \multicolumn{4}{|l|}{ Prednisone } \\
\hline Taking prednisone now & 3.9 & 5.3 & $<0.001$ \\
\hline No prednisone now & 3.5 & 4.8 & $<0.001$ \\
\hline $\mathrm{p}$ Value* & 0.001 & 0.001 & \\
\hline \multicolumn{4}{|l|}{ Biologicals } \\
\hline Taking biologicals now & 3.7 & 4.4 & $<0.001$ \\
\hline No biologicals now & 3.7 & 5.2 & $<0.001$ \\
\hline p Value* & 0.63 & $<0.001$ & \\
\hline
\end{tabular}




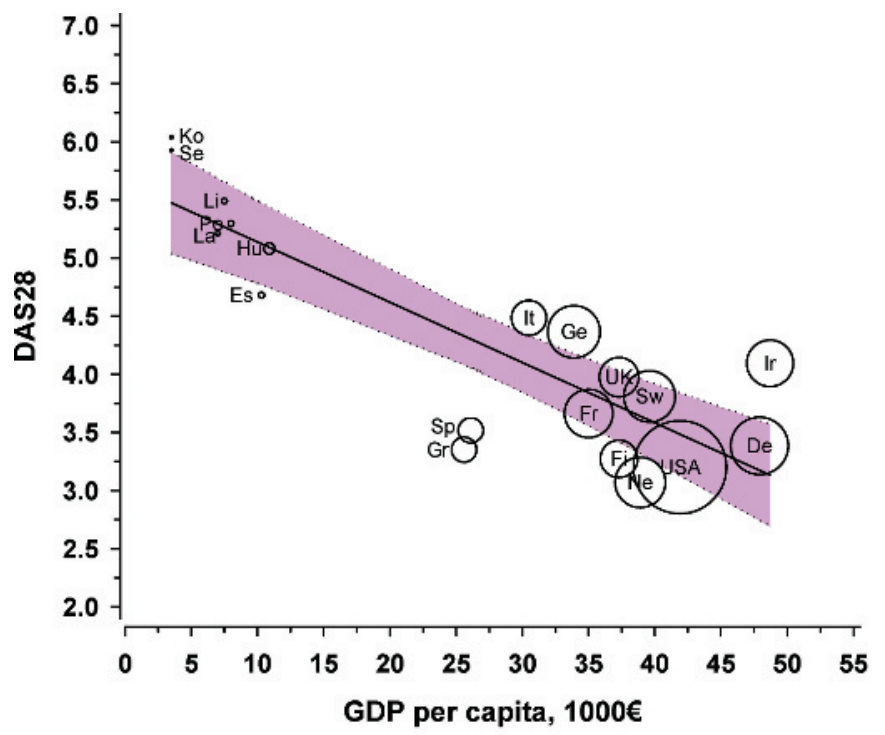

Figure 1 Association between gross domestic product per capita (GDP) and disease activity score in 28 joints (DAS28) in 18 European countries and the USA in the QUEST-RA study. The correlation of GDP with DAS28 is $r=-0.85(95 \% \mathrm{Cl}-0.63$ to -0.94$)$; indicated with colour. GDP is expressed as $1000 €$ per capita. DAS28 ranges from 0 to 9.1 (low-high disease activity). The area of the disk is proportional to the total national health expenditure of each country in 2004. De, Denmark; Es, Estonia; Fi, Finland; Fr, France; Ge, Germany; Gr, Greece; Hu, Hungary; Ir, Ireland; It, Italy; Ko, Kosovo; La, Latvia; Li, Lithuania; Ne, The Netherlands; Po, Poland; Se, Serbia; Sp, Spain; Sw, Sweden.

socioeconomic status with poor health and high mortality may be explained as much or ever better by psychosocial and behavioural variables as by "medical" variables, according to a "biopsychosocial model" to complement a biomedical model. ${ }^{23} 242728$ In the present study, psychological distress appeared significantly greater in "low GDP" than in "high GDP" countries.

Several limitations are seen in this study. First, cross-sectional QUEST-RA data cannot address definitively whether the biology of RA is more severe in less wealthy versus wealthy countries. GDP may serve as a surrogate marker for many variables, some related and others unrelated directly to medical care.

Second, a limited number of patients were included per country. Nonetheless, results were quite similar among clinics within each country. ${ }^{10}$ Furthermore, it is not possible to obtain optimal clinical information on large numbers of patients, with accurate physical examination and physician-recorded diagnosis for diseases such as RA, using only surveys. RA is not diagnosed according to a single "gold standard" measure as seen for hypertension or diabetes, but according to a set of measures, requiring a knowledgeable clinician.

Third, it is possible that only RA patients with poor clinical status visit clinics in countries with lower GDP, and patients with better status in rich countries seek medical care. While this possibility cannot be excluded, the study was designed to incorporate a cross section of patients seen in various countries. Clinical trials in patients with RA tend to be performed in countries with lower GDP at this time, as most patients in countries with higher GDP do not meet inclusion criteria, ${ }^{29}$ indicating the likelihood of an accurate representation of the present study.

These results illustrate the potential value of collaborative databases, with identical database architecture, to provide an opportunity to study associations between disease characteristics, therapies and outcomes at many sites in many countries with different economic levels. The OUEST-RA database may appear somewhat complex, although the collected data were regarded as consistent with appropriate good patient care. The only payments made to physicians were to cover the costs of materials and mailing. Similar efforts could be conducted at low cost for many diseases and add useful information regarding clinical status, prognosis and monitoring.

The status of patients with RA has been found to be significantly better in recent years than in previous decades..$^{30-32}$ However, almost all of the published data have been derived from western European and north American nations. The data presented in this report, indicating disparities with other countries, present an important challenge. While it is possible that other nations may "catch up" over the next decade to advances in the wealthier nations at this time, disparities may continue to exist. Public health efforts would appear potentially to be as important as the introduction of new therapies to treat RA. ${ }^{33}$

Further research is needed to understand better the structure (demographic, macroeconomic), process (clinical and treatment variables) and outcomes (mortality, functional and work status), which may contribute to differences in quality of care for patients with RA in different countries. Recognition of major differences in outcomes can lead to more informed efforts to improve the structure and process of care. The ultimate goal of these efforts is to improve outcomes for patients with RA in all countries.

Author affiliations: ${ }^{1}$ Jyväskylä Central Hospital, Jyväskylä; Medcare Oy, Äänekoski, Finland: ${ }^{2}$ Unit of Family Practice, Jyväskylä Central Hospital, Jyväskylä, and ORTON, Rehabilitation Unit, Helsinki, Finland; ${ }^{3}$ NYU Hospital for Joint Diseases, New York, NY, USA; ${ }^{4}$ Hospital San Juan Bautista, Catamarca, Argentina; ${ }^{5}$ Universidade do Estado do Rio de Janeiro, Rio de Janeiro, Brazil; ${ }^{6}$ Riverside Professional Center, Sydney, NS, Canada; ${ }^{7}$ Copenhagen Univ Hospital at Hvidovre, Hvidovre, Denmark; ${ }^{8}$ East-Tallinn Central Hospital, Tallinn, Estonia; ${ }^{9}$ North Karelia Central Hospital, Joensuu, Finland;

${ }^{10}$ Dijon University Hospital, University of Burgundy and INSERM U887, Dijon, France;

${ }^{11}$ University of loannina, loannina, Greece; ${ }^{12}$ Schlosspark-Klinik, Berlin, Germany;

${ }^{13}$ Polyclinic of the Hospitaller Brothers of St. John of God in Budapest, Budapest, Hungary; ${ }^{14}$ St. Vincent University Hospital, Dublin, Ireland; ${ }^{15}$ Our Lady's Hospice, Dublin, Ireland; ${ }^{16}$ Santa Chiara Hospital, Pisa, Italy; ${ }^{17}$ Rheumatology Department, Pristine, Kosovo; ${ }^{18}$ Pauls Stradina Clinical University Hospital, Riga, Latvia; ${ }^{19}$ Institute of Experimental and Clinical Medicine at Vinnius University, Vilnius, Lithuania; ${ }^{20}$ Sint Franciscus Gasthuis Hospital, Rotterdam, Netherlands; ${ }^{21}$ Medical University in Bialystok, Bialystok, Poland; ${ }^{22}$ Early Arthritis Department, Institute of Rheumatology of Russian Academy of Medical Sciences, Moscow, Russia; ${ }^{23}$ Rheumatology Institut, Niska Banja, Serbia; ${ }^{24}$ Hospital de Gran Canaria Dr. Negrin, Las Palmas, Spain; ${ }^{25}$ Uppsala University Hospital, Uppsala, Sweden; ${ }^{26}$ Gazi University Medical Faculty, Ankara, Turkey; ${ }^{27}$ Dubai Bone and Joint Center, Dubai, United Arab Emirates;

${ }^{28}$ American Hospital Dubai, Dubai, United Arab Emirates; ${ }^{29}$ University Medical Faculty, Charing Cross Hospital, London, UK

Acknowledgements: The authors are grateful to all investigators in the QUEST-RA project (whose names are listed in a supplemental file available online only).

Funding: TS has received grants from Central Finland Health Care District and Heinola Rheumatism Foundation Hospital (EVO grants). Funding sources did not participate in the study design and the collection, management, analysis and interpretation of data, and preparation, review, or approval of the manuscript and the decision to submit it for publication.

Competing interests: None.

Ethics approval: The study was carried out in compliance with the Helsinki Declaration. Ethics Committees or Internal Review Boards of participating institutes approved the study.

Patient consent: Obtained.

Contributors: Study design: TS, TP, HK. Acquisition of data: The entire QUEST-RA study group. Analyses and interpretation of data: TS, HK, TP. Preparation of the manuscript and approval of the final version: The entire QUEST-RA study group. All researchers had access to all the data. TS takes responsibility for the integrity of the data and the accuracy of the data analysis.

Provenance and peer review: Not commissioned; externally peer reviewed. 


\section{REFERENCES}

1. Marmot MG, Rose G, Shipley M, Hamilton PJS. Employment grade and coronary heart disease in British civil servants. J Epidemiol Commun Health 1978;32:244-9.

2. Pincus T, Callahan LF, Burkhauser RV. Most chronic diseases are reported more frequently by individuals with fewer than 12 years of formal education in the age 1864 United States population. J Chronic Dis 1987;40:865-74.

3. Adler NE, Boyce WT, Chesney MA, Folkman S, Syme SL. Socioeconomic inequalities in health: no easy solution. JAMA 1993:269:3140-5.

4. Pappas G, Queen S, Hadden W, Fisher G. The increasing disparity in mortality between socioeconomic groups in the United States, 1960 and 1986. N Engl J Med 1993;329:103-9.

5. Pincus T, Keysor J, Sokka T, Krishnan E, Callahan LF. Patient questionnaires and formal education level as prospective predictors of mortality over 10 years in $97 \%$ of 1416 patients with rheumatoid arthritis from 15 United States private practices. J Rheumatol 2004:31:229-34.

6. Minkler M, Fuller-Thomson E, Guralnik JM. Gradient of disability across the socioeconomic spectrum in the United States. N Engl J Med 2006:355:695-703.

7. Kunst AE, Mackenbach JP. Size of mortality differences associated with educational level in nine industrialized countries. Am J Public Health 1994:84:932-7.

8. Kim D, Kawachi I, Hoorn SV, Ezzati M. Is inequality at the heart of it? Cross-country associations of income inequality with cardiovascular diseases and risk factors. Soc Sci Med 2008;66:1719-32.

9. Mackenbach JP, Stirbu I, Roskam AJ, Schaap MM, Menvielle G, Leinsalu M, et al. Socioeconomic inequalities in health in 22 European countries. $N$ Engl $\mathrm{J}$ Med 2008;358:2468-81

10. Sokka T, Kautiainen H, Toloza S, Mäkinen H, Verstappen SMM, Hetland ML, et al. QUEST-RA: quantitative clinical assessment of patients with rheumatoid arthritis seen in standard rheumatology care in 15 countries. Ann Rheum Dis 2007:66:1491-6.

11. Sokka T, Hetland ML, Makinen H, Kautiainen H, Horslev-Petersen K, Luukkainen RK et al. Remission and rheumatoid arthritis: data on patients receiving usual care in twenty-four countries. Arthritis Rheum 2008;58:2642-51.

12. Prevoo MLL, van't Hof MA, Kuper HH, van Leeuwen MA, van de Putte LBA, van Riel PLCM. Modified disease activity scores that include twenty-eight-joint counts: development and validation in a prospective longitudinal study of patients with rheumatoid arthritis. Arthritis Rheum 1995;38:44-8.

13. Pincus T, Brooks RH, Callahan LF. A proposed standard protocol to evaluate rheumatoid arthritis (SPERA) that includes measures of inflammatory activity, joint damage, and longterm outcomes. J Rheumatol 1999;26:473-80.

14. Fries JF, Spitz P, Kraines RG, Holman HR. Measurement of patient outcome in arthritis. Arthritis Rheum 1980;23:137-45.

15. Pincus T, Swearingen C, Wolfe F. Toward a multidimensional health assessment questionnaire (MDHAO): assessment of advanced activities of daily living and psychological status in the patient friendly health assessment questionnaire format. Arthritis Rheum 1999:42:2220-30.
16. http://www.imf.org/external/ns/cs.aspx?id=28 (accessed 12 December 2008).

17. Micheli A, Coebergh JW, Mugno E, Massimiliani E, Sant M, Oberaigner W, et al. European health systems and cancer care. Ann Oncol 2003;14:v41-v60.

18. WHO. Preventing chronic diseases. a vital investment: WHO global report. Geneva: World Health Organization, 2005.

19. Abegunde DO, Mathers CD, Adam T, Ortegon M, Strong K. The burden and costs of chronic diseases in low-income and middle-income countries. Lancet 2007;370:1929-38.

20. Pincus T, Callahan LF. Formal education as a marker for increased mortality and morbidity in rheumatoid arthritis. J Chronic Dis 1985;38:973-84.

21. Greenberger NJ, Davies NE, Maynard EP, Wallerstein RO. Universal access to health care in America: a moral and medical imperative. Ann Intern Med 1990;112:637-8.

22. Andrulis DP. Access to care is the centerpiece in the elimination of socioeconomic disparities in health. Ann Intern Med 1998;129:412-16.

23. Pincus T, Esther R, DeWalt DA, Callahan LF. Social conditions and self-management are more powerful determinants of health than access to care. Ann Intern Med 1998;129:406-11.

24. Engel GL. The need for a new medical model: a challenge for biomedicine. Science 1977;196:129-36

25. DeWalt DA, Pincus T. The legacies of Rudolf Virchow: cellular medicine in the 20th century and social medicine in the 21st century. Isr Med Assoc J 2003:5:395-7.

26. Pincus T. Formal educational level - a marker for the importance of behavioral variables in the pathogenesis, morbidity, and mortality of most diseases? [editorial]. J Rheumatol 1988:15:1457-60.

27. Adler NE, Epel ES, Castellazzo G, Ickovics JR. Relationship of subjective and objective social status with psychological and physiological functioning: preliminary data in healthy white women. Health Psychol 2000;19:586-92.

28. Marmot MG, Shipley MJ, Hemingway H, Head J, Brunner EJ. Biological and behavioural explanations of social inequalities in coronary heart disease: the Whitehall II study. Diabetologia 2008;51:1980-8.

29. Sokka T, Pincus T. Eligibility of patients in routine care for major clinical trials of antitumor necrosis factor alpha agents in rheumatoid arthritis. Arthritis Rheum 2003;48:313-18.

30. Krishnan E, Fries JF. Reduction in long-term functional disability in rheumatoid arthritis from 1977 to 1998: a longitudinal study of 3035 patients. Am J Med 2003; 115:371-6.

31. Pincus T, Sokka T, Kautiainen H. Patients seen for standard rheumatoid arthritis care have significantly better articular, radiographic, laboratory, and functional status in 2000 than in 1985. Arthritis Rheum 2005;52:1009-19.

32. Uhlig T, Heiberg T, Mowinckel P, Kvien TK. Rheumatoid arthritis is milder in the new millennium: health status in patients with rheumatoid arthritis 1994-2004. Ann Rheum Dis 2008;67:1710-15.

33. Emery P. Treatment of rheumatoid arthritis. BMJ 2006:332:152-5.

\section{Drug and Therapeutics Bulletin (DTB)}

\section{Your key source of unbiased, independent advice}

For over 45 years DTB has been an independent, indispensable part of evidence-based clinical practice. DTB offers healthcare professionals detailed assessment of, and practical advice on, individual medicines and other treatments, groups of treatment and the overall management of disease.

DTB is now also available online at http://dtb.bmj.com:

- browse or search all DTB content from the latest issue back to 1994

- email alerting, sophisticated searching, RSS feeds and full text links from cited references

- interactive services such as My Folders for quick access to articles that you have viewed previously and My Searches to save and re-use useful searches

- comment online on any DTB article

To subscribe, or for further information, please visit http://dtb.bmj.com 